\title{
X-Ray Structure Characterization of Palladium(II) Ternary Complexes of Pyridinedicarboxylic and Phthalic Acid with Phenanthroline and Bipyridine
}

\author{
Yue $\mathrm{WANG}^{a}$ and Nobuo OKABE ${ }^{*, b}$ \\ ${ }^{a}$ Lab of Inorganic Chemistry, China Pharmaceutical University; Nanjing 210009, China: and ${ }^{b}$ Faculty of Pharmaceutical \\ Sciences, Kinki University; 3-4-1 Kowakae, Higashiosaka, Osaka 577-8502, Japan. \\ Received October 25, 2004; accepted January 26, 2005
}

\begin{abstract}
The crystal structures of the series of four ternary complexes, $[\mathrm{Pd}(\mathrm{phen})(2,6-\mathrm{PDCA})] \cdot 4 \mathrm{H}_{2} \mathrm{O}(1)(\mathrm{phen}=$ 1,10-phenanthroline; 2,6-PDCA =2,6-pyridinedicarboxylic acid), $[\mathrm{Pd}(\mathrm{bpy})(2,3-\mathrm{PDCA})] \cdot 3 \mathrm{H}_{2} \mathrm{O}(2) \quad\left(\mathrm{bpy}=2,2^{\prime}-\right.$ bipyridineand; 2,3-PDCA=2,3-pyridinedicarboxylic acid) and $[\mathrm{Pd}(\mathrm{phen})(\mathrm{PHT})] \cdot 2.5 \mathrm{H}_{2} \mathrm{O}(3)(\mathrm{PHT}=o$-phthalic acid ) and $[\mathrm{Pd}(\mathrm{bpy})(\mathrm{PHT})] \cdot 1.5 \mathrm{H}_{2} \mathrm{O}$ (4), are determined and the coordination modes of palladium(II) ternary complexes are characterized. All complexes take the mononuclear Pd(II) complexes, in which central Pd(II) atom of each complex has a similar distorted square-planar four coordination geometry. In all complexes, the aromatic heterocyclic compounds, phen and bpy, behave as a bidentate $N, N^{\prime}$ ligand. In the complex 1 and 2, 2,6-PDCA and 2,3-PDCA behave as a bidentate $N, O$ ligand, and in complex 3 and 4, PHT behaves as a bidentate O, O' ligand.
\end{abstract}

Key words palladium(II) complex; coordination modes; $\mathrm{X}$-ray crystal analysis

The consequence of similar coordination behavior of palladium(II) and platinum(II) induced the much more interesting on the development of the antitumor palladium(II) complexe. ${ }^{1,2)}$ The $\mathrm{Pd}(\mathrm{II})$ analogues of $\mathrm{Pt}(\mathrm{II})$ complexes, such as cisplatin or carboplatin which have been efficiently used as therapeutic anticancer drugs are the ideal models for studies of the squareplanar complex. ${ }^{3)}$ One of a recent study demonstrates a $\mathrm{Pd}(\mathrm{II})$ complex with an aromatic heterocyclic ligand, $[\mathrm{Pd}($ bpy)(CBDCA)](CBDCA = 1,1-cyclobutanedicarboxylate) has better cytotoxic activity than cisplatin against $\mathrm{P}_{388}$ lymphocytic leukaemia cells. ${ }^{4}$ Even the principle mechanism of its antitumor property is not known, it is known that some kinds of the aromatic heterocycles can stack with nucleobases and then enhance the complex formation with DNA, which is the target in the chemotherapy of tumor. ${ }^{5)}$

Our group have succeeded in synthesizing series of palladium(II) ternary complexes having cis-planar four coordination geometry with $\mathrm{N}$ and $\mathrm{O}$ atoms and determining their structures, in which the aromatic heterocyclic ligands, bpy and phen has been structurally clarified as bidentate $\mathrm{N}, \mathrm{N}^{\prime}$ ligands and CBDCA, catechol or 2,3-naphthalenediol as the dianionic bidentate $\mathrm{O}, \mathrm{O}^{\prime}$ ligands. ${ }^{6-8)}$

As a continued research, we aimed to characterize the coordination modes of $\mathrm{Pd}(\mathrm{II})$ ternary complexes of the aromatic heterocyclic bidentate $\mathrm{N}, \mathrm{N}^{\prime}$ ligand with a dianionic pyridinedicarboxylate and its structural analogue, benzenedicarboxylate ligand.

By this reason, in this study, we have synthesized $\operatorname{Pd}(\mathrm{II})$ ternary complexes of the aromatic heterocyclic ligands, phen and bpy, with pyridinedicarboxylate ligands, 2,6-PDCA, 2,3PDCA and their analogous benzenedicarboxylate ligand, PHT. And the structures of the following four ternary complexes (Fig. 1) have been determined by X-ray analysis: [Pd(phen)(2,6-PDCA)] $4 \mathrm{H}_{2} \mathrm{O}$ (1), [Pd(bpy)(2,3-PDCA)] $3 \mathrm{H}_{2} \mathrm{O}(\mathbf{2}),[\mathrm{Pd}($ phen $)(\mathrm{PHT})] \cdot 2.5 \mathrm{H}_{2} \mathrm{O}(\mathbf{3}),[\mathrm{Pd}(\mathrm{bpy})(\mathrm{PHT})]$. $1.5 \mathrm{H}_{2} \mathrm{O}(4)$.

PDCAs are naturally occurring catabolites of amino acid or bacteria, and they might contribute to the ability of bacteria to degrade synthetic PHTs. ${ }^{9)}$ Many kinds of transition metal PHTs complexes have been reported, but its $\mathrm{Pd}(\mathrm{II})$ complexes have not been clarified yet.

\section{Experimental}

Materials Analytical grade of 1,10-phenanthroline (phen), 2,2'bipyridyl(bpy), 2,6-pyridinedicarboxylic acid (2,6-PDCA), 2,3-pyridinedicarboxylic acid (2,3-PDCA), $o$-phthalic acid (PHT), palladium(II) acetate and $N, N^{\prime}$-dimethylformamide (DMF), were obtained from Wako Pure Chemicals, Industries Ltd. (Osaka, Japan).

Preparation of the Single Crystals of Complexes All single crystals of the complexes were prepared with palladium(II) acetate at $(1: 1: 1)$ mole ratio of the metal, phen (or bpy) and the other ligands 2,6-PDCA (or 2,3-
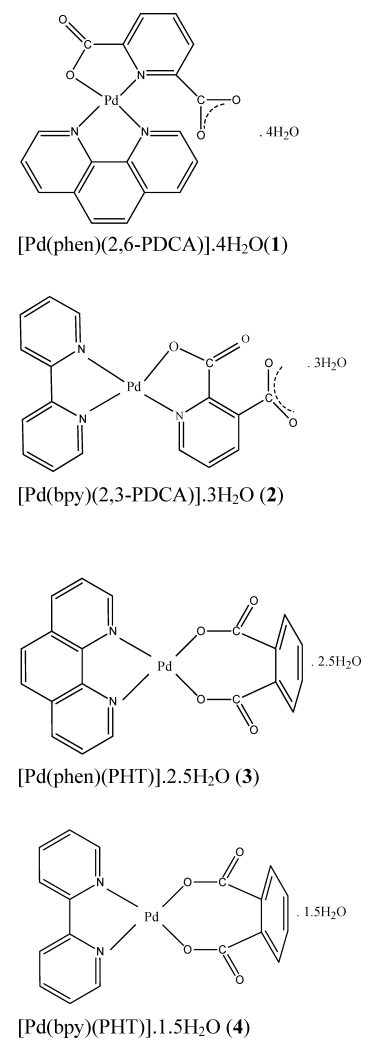

Fig. 1. Chemical Structures of Four Complexes $1-4$ 
Table 1. Crystal Data and Structure Refinement for Compounds $1-4$

\begin{tabular}{lllll}
\hline \hline & \multicolumn{1}{c}{$\mathbf{1}$} & \multicolumn{1}{c}{$\mathbf{2}$} & $\mathbf{3}$ & $\mathbf{4}$ \\
\hline Formula & $\mathrm{C}_{19} \mathrm{H}_{11} \mathrm{~N}_{3} \mathrm{O}_{4} \mathrm{Pd} \cdot 4 \mathrm{H}_{2} \mathrm{O}$ & $\mathrm{C}_{17} \mathrm{H}_{11} \mathrm{~N}_{3} \mathrm{O}_{4} \mathrm{Pd} \cdot 3 \mathrm{H}_{2} \mathrm{O}$ & $\mathrm{C}_{20} \mathrm{H}_{12} \mathrm{~N}_{2} \mathrm{O}_{4} \mathrm{Pd} \cdot 2.5 \mathrm{H}_{2} \mathrm{O}$ & $\mathrm{C}_{18} \mathrm{H}_{12} \mathrm{~N}_{2} \mathrm{O}_{4} \mathrm{Pd} \cdot 1.5 \mathrm{H}_{2} \mathrm{O}$ \\
Formula weight & 523.79 & 481.76 & 495.77 & 453.74 \\
Crystal system & monoclinic & monoclinic & monoclinic \\
Space group & $\mathrm{P} 21 / \mathrm{a}$ & $\mathrm{P}-1$ & $\mathrm{P} 21 / \mathrm{n}$ & $\mathrm{P} 21 / \mathrm{n}$ \\
$a(\AA)$ & $8.232(4)$ & $7.008(5)$ & $7.218(7)$ & $7.090(9)$ \\
$b(\AA)$ & $24.44(2)$ & $9.986(8)$ & $13.21(2)$ & $13.44(2)$ \\
$c(\AA)$ & $10.006(8)$ & $13.520(10)$ & $19.96(2)$ & $17.82(2)$ \\
$\alpha\left({ }^{\circ}\right)$ & 90.00 & $99.30(3)$ & 90.00 & 90.00 \\
$\beta\left({ }^{\circ}\right)$ & $97.83(3)$ & $94.38(3)$ & $97.45(3)$ & $92.40(6)$ \\
$\gamma\left({ }^{\circ}\right)$ & 90.00 & $107.86(2)$ & 90.00 & 90.00 \\
$V\left(\AA^{3}\right)$ & $1994(2)$ & $880.7(12)$ & $1887(4)$ & $1697(4)$ \\
$Z$ & 4 & 2 & 4 & 4 \\
$D_{\text {calc }}\left(\mathrm{g} / \mathrm{cm}^{-3}\right)$ & 1.751 & 1.817 & 1.745 & 1.776 \\
$T(\mathrm{~K})$ & 296.1 & 296.1 & 296.1 & 296.1 \\
$F(000)$ & 1056.0 & 484.0 & 996 & 908.0 \\
Crystal size (mm) & $0.30 \times 0.10 \times 0.05$ & $0.25 \times 0.05 \times 0.05$ & $0.30 \times 0.10 \times 0.10$ & $0.25 \times 0.05 \times 0.05$ \\
Absorption coefficient $\left(\mathrm{mm}^{-1}\right)$ & 0.986 & 1.103 & 1.029 & 1.130 \\
Reflection measured/unique & $18701 / 4504$ & $8719 / 3991$ & $17948 / 4268$ & $14992 / 3852$ \\
Observed reflections & 3017 & 2670 & 3156 & 1942 \\
$\mathrm{R}\left(F^{2}>2 \sigma\left(F^{2}\right)\right)$ & 0.0230 & 0.0630 & 0.0250 & 0.0550 \\
$w \mathrm{R}\left(F^{2}\right)$ & 0.0530 & 0.1830 & 0.0740 & 0.1480 \\
Goodness of fit & 0.925 & 1.001 & 1.050 & 0.902 \\
No. of variables & 279 & 273 & 273 & 243 \\
& & &
\end{tabular}

PDCA, PHT). The typical synthesis is described below:

[Pd(phen)(2,6-PDCA)] $4 \mathrm{H}_{2} \mathrm{O}(\mathbf{1}): 2 \mathrm{mg}(0.01 \mathrm{mmol})$ phen was mixed with $2.5 \mathrm{mg}(0.01 \mathrm{mmol}) \mathrm{Pd}(\mathrm{II})$ acetate in $5 \mathrm{ml}$ DMF solvent for about $15 \mathrm{~min}$. Then $1.9 \mathrm{mg}(0.01 \mathrm{mmol}) 2,6-\mathrm{PDCA}$ was added to such mixture and reacted for no less than $30 \mathrm{~min}$. The yellow solution was placed at the room temperature and kept for slow evaporation. Two weeks later yellow needlelike crystals suitable for X-ray diffraction studies were obtained from mother liquor.

[Pd(bpy)(2,3-PDCA)] $3 \mathrm{H}_{2} \mathrm{O}(\mathbf{2}): 1.7 \mathrm{mg}(0.01 \mathrm{mmol})$ bpy was mixed with $2.5 \mathrm{mg}(0.01 \mathrm{mmol}) \mathrm{Pd}(\mathrm{II})$ acetate in $5 \mathrm{ml}$ DMF solvent for about $15 \mathrm{~min}$. Then $1.9 \mathrm{mg}(0.01 \mathrm{mmol})$ 2,3-PDCA was added to such mixture and reacted for no less than $30 \mathrm{~min}$. The light yellow solution was placed at the room temperature and kept for slow evaporation. One week later light yellow needle-like crystals suitable for X-ray diffraction studies were obtained from mother liquor.

$[\mathrm{Pd}($ phen $)(\mathrm{PHT})] \cdot 2.5 \mathrm{H}_{2} \mathrm{O}(\mathbf{3}): 2 \mathrm{mg}(0.01 \mathrm{mmol})$ phen was mixed with $2.5 \mathrm{mg}(0.01 \mathrm{mmol}) \mathrm{Pd}(\mathrm{II})$ acetate in $5 \mathrm{ml}$ DMF solvent for about $15 \mathrm{~min}$. Then $1.9 \mathrm{mg}(0.01 \mathrm{mmol})$ PHT was added to such mixture and reacted for no less than $30 \mathrm{~min}$. The yellow solution was placed at the room temperature and kept for slow evaporation. One week later yellow needle-like crystals suitable for X-ray diffraction studies were obtained from mother liquor.

$[\mathrm{Pd}(\mathrm{bpy})(\mathrm{PHT})] \cdot 1.5 \mathrm{H}_{2} \mathrm{O}(4): 1.7 \mathrm{mg}(0.01 \mathrm{mmol})$ bpy was mixed with $2.5 \mathrm{mg}(0.01 \mathrm{mmol}) \mathrm{Pd}(\mathrm{II})$ acetate in $5 \mathrm{ml}$ DMF solvent for about $15 \mathrm{~min}$. Then $1.9 \mathrm{mg}(0.01 \mathrm{mmol})$ PHT was added to such mixture and reacted for no less than $30 \mathrm{~min}$. The light yellow solution was placed at the room temperature and kept for slow evaporation. One week later light yellow needle-like crystals suitable for X-ray diffraction studies were obtained from mother liquor.

X-Ray Crystal Analysis The X-ray measurements were made on a Rigaku RAXIS RAPID diffractometer with a graphite monochromatised Mo $K \alpha$ radiation $(\lambda=0.71069 \AA)$ using $\omega$ scan mode. A summary of the crystallographic data and structure refinements is given in Table 1 . The data were corrected for Lorentz and polarization effects. The structure was solved by direct methods ${ }^{10)}$ using the Crystal Structure ${ }^{11)}$ software package. The refinement was performed using SHELXL-97. ${ }^{12)}$ All $\mathrm{H}$ atoms except those of water molecules were located from difference Fourier maps and placed at idealized positions and treated as riding, with $\mathrm{C}-\mathrm{H}$ distance of 0.93 and $U_{\text {iso }}(\mathrm{H})$ values equal to $1.2 U_{\text {eq }}(\mathrm{C})\left(U_{\text {eq }}\right.$ is the equivalent isotropic displacement parameter for the pivot atom).

The function of $\Sigma w\left(F_{\mathrm{o}}^{2}-F_{\mathrm{c}}^{2}\right)^{2}$ was minimized by using the weight scheme of $\quad w=1 /\left[\sigma^{2}\left(F_{\mathrm{o}}^{2}\right)+(a P)^{2}+b P\right]$, where $P=\left(F_{\mathrm{o}}^{2}+2 F_{\mathrm{c}}^{2}\right) / 3$. Final $R$ $\left[=\Sigma\left(\left|F_{\mathrm{o}}\right|-\left|F_{\mathrm{c}}\right|\right) / \Sigma\left|F_{\mathrm{o}}\right|\right], R w\left[=\left(\Sigma w\left(\left|F_{\mathrm{o}}\right|-\mid F_{\mathrm{c}}\right)^{2} / \Sigma w\left|F_{\mathrm{o}}\right|^{2}\right)^{1 / 2}\right]$ and $\mathrm{S}$ (goodness of fit) $\left[=\left(\Sigma w\left(\left|F_{\mathrm{o}}\right|-\mid F_{\mathrm{c}}\right)^{2} /(M-N)^{1 / 2}\right)\right.$, where $M=$ no. of reflections and $N=$ no. of variables used for the refinement] are given in Table 1. Anisotropic displace- ment coefficients were refined for all non-hydrogen atoms. Selected bond distances and angles are listed in Tables $2-5$, respectively. Because of the hygroscopic ligands, all four crystals contained solvated water molecules. $\mathrm{H} 15, \mathrm{H} 16$ atom of water $\mathrm{O} 6$ molecule and $\mathrm{H} 18, \mathrm{H} 19$ atom of water $\mathrm{O} 7 \mathrm{~mol}-$

Table 2. Bond Distances $(\AA)$ and Angles $\left({ }^{\circ}\right)$ for $[\operatorname{Pd}($ phen $)(2,6-P D C A)]$. $4 \mathrm{H}_{2} \mathrm{O}(\mathbf{1})$

\begin{tabular}{lrll}
\hline \hline $\begin{array}{c}\text { Bond distances } \\
\text { Pd1-O1 }\end{array}$ & $1.964(1)$ & O4-C7 & $1.247(3)$ \\
Pd1-N1 & $2.067(2)$ & N1-C1 & $1.359(2)$ \\
Pd1-N2 & $2.052(2)$ & N1-C5 & $1.346(3)$ \\
Pd1-N3 & $2.002(2)$ & N2-C8 & $1.325(3)$ \\
O1-C6 & $1.296(3)$ & N2-C12 & $1.366(3)$ \\
O2-C6 & $1.212(3)$ & N3-C13 & $1.359(3)$ \\
O3-C7 & $1.231(3)$ & N3-C19 & $1.329(3)$ \\
Bond angles & & & \\
O1-Pd1-N1 & $81.08(6)$ & C1-N1-Pd1 & $109.4(1)$ \\
O1-Pd1-N2 & $168.51(7)$ & C5-N1-Pd1 & $132.0(1)$ \\
O1-Pd1-N3 & $90.65(7)$ & C8-N2-Pd1 & $131.2(1)$ \\
N1-Pd1-N2 & $107.72(7)$ & C12-N2-Pd1 & $111.7(1)$ \\
N1-Pd1-N3 & $171.14(7)$ & C13-N3-Pd1 & $114.0(1)$ \\
N2-Pd1-N3 & $80.90(7)$ & C19-N3-Pd1 & $126.7(2)$ \\
\hline
\end{tabular}

Table 3. Bond Distances $(\AA)$ and Angles $\left({ }^{\circ}\right)$ for $[\operatorname{Pd}($ bpy $)(2,3-\mathrm{PDCA})]$. $3 \mathrm{H}_{2} \mathrm{O}(\mathbf{2})$

\begin{tabular}{lrll}
\hline \hline Bond distances & & & \\
Pd1-O1 & $1.979(6)$ & O4-C17 & $1.24(1)$ \\
Pd1-N1 & $2.001(5)$ & N1-C1 & $1.34(1)$ \\
Pd1-N2 & $2.027(7)$ & N1-C5 & $1.365(9)$ \\
Pd1-N3 & $2.056(5)$ & N2-C6 & $1.336(9)$ \\
O1-C16 & $1.294(9)$ & N2-C10 & $1.38(1)$ \\
O2-C16 & $1.213(9)$ & N3-C11 & $1.352(9)$ \\
O3-C17 & $1.24(1)$ & N3-C15 & $1.338(8)$ \\
Bond angles & & & \\
O1-Pd1-N1 & $91.5(2)$ & C1-N1-Pd1 & $116.8(4)$ \\
O1-Pd1-N2 & $170.4(2)$ & C5-N1-Pd1 & $123.5(5)$ \\
O1-Pd1-N3 & $81.0(2)$ & C6-N2-Pd1 & $116.2(5)$ \\
N1-Pd1-N2 & $79.1(2)$ & C10-N2-Pd1 & $127.1(5)$ \\
N1-Pd1-N3 & $172.1(2)$ & C11-N3-Pd1 & $111.2(4)$ \\
N2-Pd1-N3 & $108.4(2)$ & C15-N3-Pd1 & $129.7(5)$ \\
C16-O1-Pd1 & $116.1(5)$ & & \\
\hline
\end{tabular}


Table 4. Bond Distances $(\AA)$ and Angles $\left({ }^{\circ}\right)$ for $[\mathrm{Pd}(\mathrm{phen})(\mathrm{PHT})] \cdot 2.5 \mathrm{H}_{2} \mathrm{O}$ (3)

\begin{tabular}{crll}
\hline \hline Bond distances & & & \\
Pd1-O1 & $2.009(2)$ & O3-C8 & $1.290(3)$ \\
Pd1-O3 & $1.981(2)$ & O4-C8 & $1.216(3)$ \\
Pd1-N1 & $2.012(2)$ & N1-C9 & $1.314(3)$ \\
Pd1-N2 & $2.007(2)$ & N1-C19 & $1.371(3)$ \\
O1-C7 & $1.284(3)$ & N2-C18 & $1.332(3)$ \\
O2-C7 & $1.231(3)$ & N2-C20 & $1.371(3)$ \\
Bond angles & & & \\
O1-Pd1-O3 & $89.57(7)$ & C7-O1-Pd1 & $121.5(1)$ \\
O1-Pd1-N1 & $95.10(7)$ & C8-O3-Pd1 & $122.0(2)$ \\
O1-Pd1-N2 & $177.38(8)$ & C9-N1-Pd1 & $129.2(2)$ \\
O3-Pd1-N1 & $172.13(7)$ & C19-N1-Pd1 & $111.9(2)$ \\
O3-Pd1-N2 & $92.91(7)$ & C18-N2-Pd1 & $128.4(2)$ \\
N1-Pd1-N2 & $82.34(8)$ & C20-N2-Pd1 & $112.1(2)$ \\
\hline
\end{tabular}

Table 5. Bond Distances $(\AA)$ and Angles $\left({ }^{\circ}\right)$ for $[\mathrm{Pd}(\mathrm{bpy})(\mathrm{PHT})] \cdot 1.5 \mathrm{H}_{2} \mathrm{O}$ (4)

\begin{tabular}{crll}
\hline \hline $\begin{array}{c}\text { Bond distances } \\
\text { Pd1-O1 }\end{array}$ & $1.991(3)$ & O3-C8 & $1.292(6)$ \\
Pd1-O3 & $2.009(3)$ & O4-C8 & $1.226(6)$ \\
Pd1-N1 & $1.999(4)$ & N1-C9 & $1.350(6)$ \\
Pd1-N2 & $1.996(4)$ & N1-C13 & $1.341(6)$ \\
O1-C7 & $1.294(6)$ & N2-C14 & $1.366(6)$ \\
O2-C7 & $1.223(5)$ & N2-C18 & $1.339(6)$ \\
Bond angles & & & \\
O1-Pd1-O3 & $89.6(1)$ & C7-O1-Pd1 & $121.5(3)$ \\
O1-Pd1-N1 & $94.7(1)$ & C8-O3-Pd1 & $122.3(3)$ \\
O1-Pd1-N2 & $173.7(1)$ & C9-N1-Pd1 & $125.3(3)$ \\
O3-Pd1-N1 & $174.3(1)$ & C13-N1-Pd1 & $114.9(3)$ \\
O3-Pd1-N2 & $94.5(1)$ & C14-N2-Pd1 & $114.6(3)$ \\
N1-Pd1-N2 & $80.9(2)$ & C18-N2-Pd1 & $125.4(3)$
\end{tabular}

Table 6. Hydrogen Bonds in Compounds $\mathbf{1}-\mathbf{4}$

\begin{tabular}{|c|c|c|c|c|c|}
\hline Donor (D-H) & Acceptor (A) & Sym. code of A & $\mathrm{D} \cdots \mathrm{A}(\AA)$ & $\mathrm{H} \cdots \mathrm{A}(\AA)$ & $\mathrm{D}-\mathrm{H} \cdots \mathrm{A}\left({ }^{\circ}\right)$ \\
\hline \multicolumn{6}{|l|}{ Compound 1} \\
\hline $\mathrm{O} 5$ & $\mathrm{O} 4$ & $+x,+y,+z$ & $2.732(2)$ & 1.82 & 179 \\
\hline O5 & $\mathrm{O} 4$ & $-1 / 2+x, 1 / 2-y,+z$ & $2.732(3)$ & 1.79 & 159 \\
\hline O6 & O5 & $+x,+y,+z$ & $2.682(3)$ & 1.71 & 165 \\
\hline O6 & $\mathrm{O} 7$ & $+x,+y,+z$ & $2.696(4)$ & 2.03 & 129 \\
\hline O6 & O7 & $1 / 2+x, 1 / 2-y,+z$ & $2.669(4)$ & 1.76 & 177 \\
\hline O7 & O8 & $+x,+y,+z$ & $2.740(3)$ & 1.82 & 177 \\
\hline O7 & O6 & $-1 / 2+x, 1 / 2-y,+z$ & $2.669(4)$ & 1.79 & 178 \\
\hline O7 & O6 & $+x,+y,+z$ & $2.696(4)$ & 1.79 & 178 \\
\hline $\mathrm{O} 8$ & $\mathrm{O} 3$ & $-1 / 2+x, 1 / 2-y,-1+z$ & $2.735(4)$ & 1.82 & 177 \\
\hline O8 & $\mathrm{O} 2$ & $3 / 2-x, 1 / 2+y, 1-z$ & $3.085(2)$ & 2.03 & 179 \\
\hline \multicolumn{6}{|l|}{ Compound 2} \\
\hline O5 & $\mathrm{O} 4$ & $+x,+y,+z$ & $2.80(1)$ & 1.87 & 169 \\
\hline O5 & $\mathrm{O} 3$ & $1+x,+y,+z$ & $2.772(8)$ & 1.84 & 168 \\
\hline O6 & O7 & $+x,+y,+z$ & $2.77(1)$ & 1.88 & 155 \\
\hline O6 & $\mathrm{O} 3$ & $1-x, 1-y, 1-z$ & $3.09(1)$ & 2.94 & 90 \\
\hline $\mathrm{O} 7$ & $\mathrm{O} 3$ & $1+x,+y,+z$ & $2.82(1)$ & 1.88 & 168 \\
\hline O7 & $\mathrm{O} 4$ & $2-x, 1-y, 1-z$ & $2.770(9)$ & 1.94 & 144 \\
\hline \multicolumn{6}{|l|}{ Compound $\mathbf{3}$} \\
\hline O5 & $\mathrm{O} 4$ & $5 / 2-x,-1 / 2+y, 3 / 2-z$ & $3.063(4)$ & 2.31 & 151 \\
\hline O5 & $\mathrm{O} 2$ & $+x,+y,+z$ & $2.846(3)$ & 2.07 & 173 \\
\hline O6 & $\mathrm{O} 7$ & $+x,+y,+z$ & $2.40(1)$ & 1.67 & 177 \\
\hline O6 & O6 & $2-x,-y, 2-z$ & $2.791(6)$ & 1.79 & 166 \\
\hline O6 & $\mathrm{O} 2$ & $+x,+y,+z$ & $2.906(4)$ & 1.92 & 178 \\
\hline O7 & O5 & $-1+x,+y,+z$ & $2.930(9)$ & 1.90 & 176 \\
\hline O7 & O5 & $2-x,-y, 2-z$ & $2.816(8)$ & 1.91 & 174 \\
\hline \multicolumn{6}{|l|}{ Compound 4} \\
\hline O5 & O6 & $+x,+y,+z$ & $2.647(5)$ & 1.84 & 152 \\
\hline O5 & O6 & $-x,-y, 1-z$ & $2.647(5)$ & 2.22 & 109 \\
\hline O6 & O5 & $+x,+y,+z$ & $2.647(5)$ & 1.95 & 141 \\
\hline O6 & O6 & $1-x,-y, 1-z$ & $2.814(7)$ & 2.15 & 117 \\
\hline O6 & $\mathrm{O} 4$ & $1 / 2-x,-1 / 2+y, 1 / 2-z$ & $2.788(6)$ & 1.81 & 167 \\
\hline
\end{tabular}

ecule in compound 1, H13, H15 atom of water O6 molecule and H18, H19 atom of water $\mathrm{O} 7$ molecule in compound 3, H15, H16 atom of water O6 molecule in compound $\mathbf{4}$ are disordered. The water $\mathrm{O} 7$ molecule in compound $\mathbf{3}$ was refined as half occupancy. For these disordered $\mathrm{H}$ atoms of the solvated water are difficult to be located in Fourier map, their locations are calculated according to the positions of the corresponding acceptor atoms. The other $\mathrm{H}$ atoms were found in Fourier map and were treated as riding as well as the disordered $\mathrm{H}$ atoms. The detailed $\mathrm{H}$-bond data are listed in Table 6.

The final atomic coordinates, anisotropic displacement coefficients, bond lengths, bond angles, torsion angles of non- $\mathrm{H}$ atoms, and the atomic coordinates of $\mathrm{H}$ atoms have been deposited in the Cambridge Crystallographic Data Centre, Cambridge University Chemical Laboratory, Cambridge CB21EW, U.K. (CCDC 251529 for [Pd(phen)(2,6-PDCA)] $4 \mathrm{H}_{2} \mathrm{O}$ (1), CCDC 251532 for [Pd(bpy)(2,3-PDCA)] $3 \mathrm{H}_{2} \mathrm{O}$ (2), CCDC 251530 for $[\mathrm{Pd}(\mathrm{phen})(\mathrm{PHT})] \cdot 2.5 \mathrm{H}_{2} \mathrm{O}(\mathbf{3}), \mathrm{CCDC} 251531$ for $[\mathrm{Pd}(\mathrm{bpy})(\mathrm{PHT})] \cdot 1.5 \mathrm{H}_{2} \mathrm{O}$
(4).

\section{Result and Discussion}

In complex 1 shown in Fig. 2, the Pd(II) atom has a distorted square-planar four-coordination geometry and is bonded to two heterocyclic $\mathrm{N}$ atoms and one pyridine $\mathrm{N}$ atom and one carboxylate $\mathrm{O}$ atom from 2,6-PDCA dianion. Another carboxylate group does not contribute to the coordination. In the square-planar coordination, atoms $\mathrm{Pd} 1, \mathrm{O} 1$, $\mathrm{N} 1, \mathrm{~N} 2, \mathrm{~N} 3$ deviate by $-0.051(1), 0.076(2),-0.084(2)$, $0.084(2),-0.109(2) \AA$, respectively, from the mean plane through these five atoms. The overall structure of complex 1 is slightly twisted with the dihedral angle between the N1 
pyridine ring and phen ring being $23.08(9)^{\circ}$, The uncoordinated carboxylate group $\mathrm{O} 3-\mathrm{C} 7-\mathrm{O} 4$ in 2,6-PCDA dianion is ionized and a little deviated from the $\mathrm{N} 1$ pyridine ring with the torsion angle of $\mathrm{N} 1-\mathrm{C} 5-\mathrm{C} 7-\mathrm{O} 3$ : $34.3(3)^{\circ}$ and N1-C5-C7-O4: $-148.2(2)^{\circ}$ as to devoid the short contact between the carboxylate $\mathrm{O}$ atoms and $\mathrm{H} 4$ atom of the phen molecule.

In the crystal packing of complex $\mathbf{1}$, the typical $\pi$ stacking interaction is present between the adjacent molecules at $(+X$, $+Y,+Z)$ and $(2-X,-Y, 1-Z)$, as shown in Fig. 3a. The five membered chelate ring $\mathrm{Pd} 1-\mathrm{N} 3-\mathrm{C} 13-\mathrm{C} 12-\mathrm{N} 2(+X,+Y$, $+Z)$ completely overlaps to the same chelate ring $(2-X,-Y$, $1-Z)$ with the interplanar distance of 3.484(2) $\AA$ between the adjacent rings, although the direct $\pi$ stacking interaction are not present. At the same time, the other five-membered chelate ring $\mathrm{Pd} 1-\mathrm{N} 1-\mathrm{C} 1-\mathrm{C} 6-\mathrm{O} 1$ in one complex molecule also overlaps to the neighboring phen ring $(2-X,-Y, 1-Z)$ with the interplanar distance value of 3.384(3) $\AA$. The similar stacking interaction between the chelate ring and the aromatic ring is also shown in the $\mathrm{Pd}(\mathrm{II})$ complex of $\left[\mathrm{PdL}^{1} \mathrm{Cl}\right] \cdot \mathrm{CH}_{2} \mathrm{Cl}_{2} \quad$ (where $\quad \mathrm{L}^{1}=2$-(2-hydroxyphenyl)-2,2' bipyridine). ${ }^{13)}$

In complex 2 shown in Fig. 4, Pd(II) atom has a distorted square-planar four coordination geometry. $\mathrm{Pd}(\mathrm{II})$ atom is

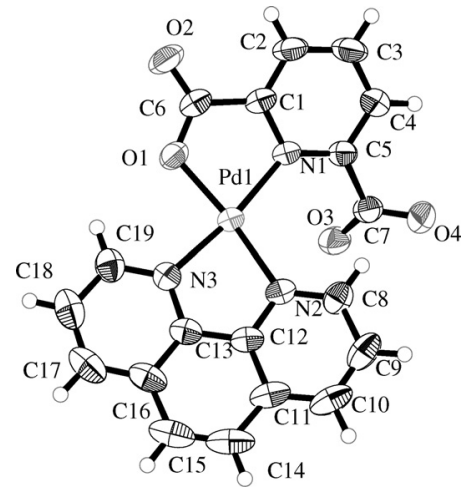

Fig. 2. ORTEPII Drawing of Complex 1, Showing 50\% Probability Displacement Ellipsoids

The water molecules involved in the unit are omitted for the clarification of the basic Pd(II) coordination geometry. bonded to two $\mathrm{N}$ atoms from the bidentate bpy ligand and one carboxylate $\mathrm{O}$ atom and one pyridine $\mathrm{N}$ atom from 2,3PDCA. Another ionized carboxylate group is also uncoordinated similar with complex 1. Pd1 atom deviates from the mean square plane $(\mathrm{N} 1 / \mathrm{N} 2 / \mathrm{O} 1 / \mathrm{N} 3)$ by the upper distance of 0.039 (3) $\AA$ comparable to complex 1. Two pyridine rings of bpy are nearly in a same plane and only twisted by $8.5(1)^{\circ}$. The overall structure of complex $\mathbf{2}$ is essentially coplanar, with the dihedral angles of pyridine ring of 2,3-PDCA and $\mathrm{N} 1$ pyridine ring and $\mathrm{N} 2$ pyridine ring being $11.0(1)^{\circ}$ and $11.2(1)^{\circ}$, respectively. In this case, the uncoordinated carboxylate group $\mathrm{O} 3-\mathrm{C} 17-\mathrm{O} 4$ is almost perpendicular to the 2,3-PDCA ring with the torsion angles: C11-C12-C17-O3: -86.4(9) ${ }^{\circ}$ and C11-C12-C17-O4: 98.0(9) ${ }^{\circ}$.

In the packing of complex 2, the shortest $\mathrm{Pd}(\mathrm{II})-\mathrm{Pd}(\mathrm{II})$ distance is 3.543(7) $\AA$. Although this metal-metal distance is a little longer than the shortest $3.369 \AA$ of $\mathrm{Pd}(\mathrm{II})-\mathrm{d}(\mathrm{II})$ or $3.381 \AA$ of $\mathrm{Pt}(\mathrm{II})-\mathrm{Pt}(\mathrm{II}),{ }^{14)}$ the weak metal-metal interaction may present. And further, as shown in Fig. 5a, the inter ring $\pi$ stacking interaction occurs, in which one of the five-membered chelate ring $\mathrm{Pd} 1-\mathrm{N} 3-\mathrm{C} 11-\mathrm{C} 16-\mathrm{O} 1$ overlaps to an adjacent $\mathrm{N} 2$ pyridine ring $(1-X,-Y, 2-Z)$ of bpy ligand with the interplanar distance of 3.424(8) $\AA$.

The molecular structure of complex 3 is shown in Fig. 6. The Pd(II) atom is located in the center of a cis-square-planar geometry and bonded to two $\mathrm{N}$ atoms of phen ligand and two $\mathrm{O}$ atoms of PTH. Pd(II) atom deviated from the mean plane

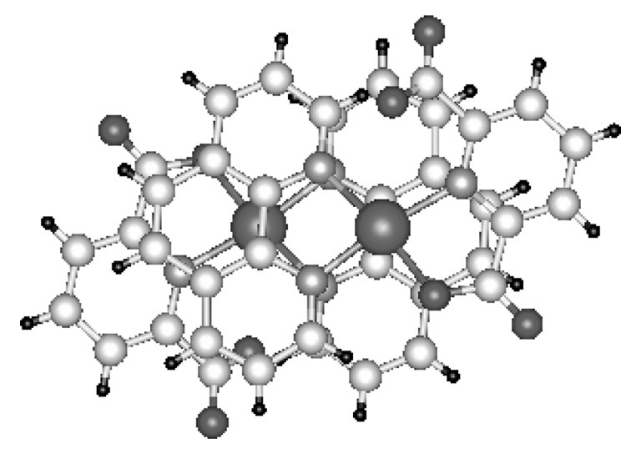

Fig. 3a. A View of $\pi-\pi$ Interaction between the Adjacent Pd(II) Moiety in Complex 1

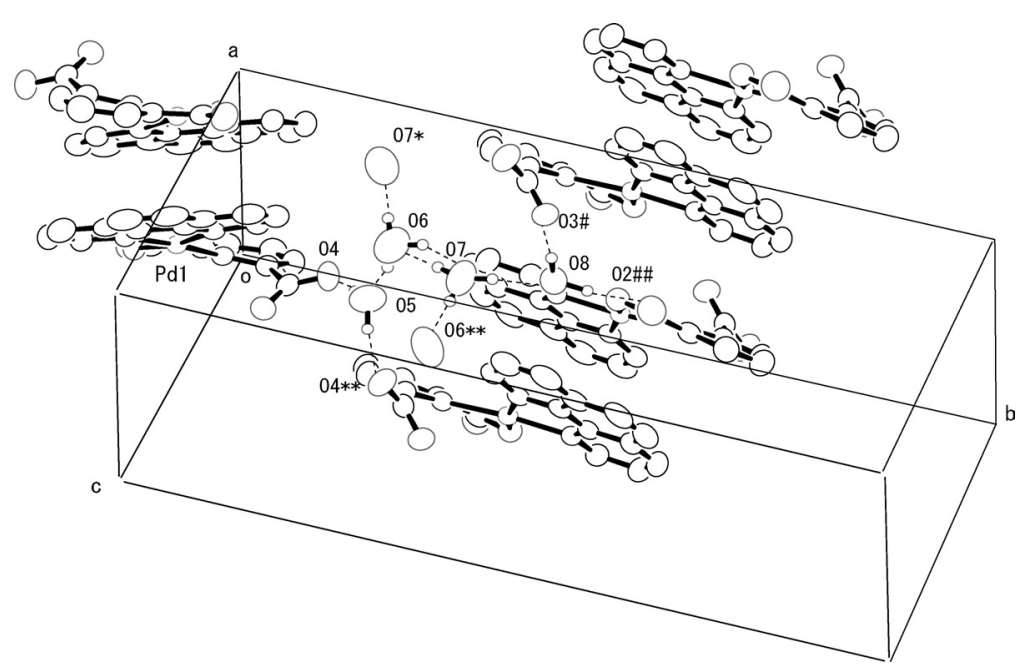

Fig. 3b. A View of Packing Pattern in Complex 1 Including H-Bonds Indicated with Dashed Lines $*: 1 / 2+X, 1 / 2-Y,+Z, * *:-1 / 2+X, 1 / 2-Y,+Z$, *: $-1 / 2+X, 1 / 2-Y,-1+Z, \#: 3 / 2-X, 1 / 2+Y, 1-Z$. 
constructed from the $\mathrm{N} 1, \mathrm{~N} 2, \mathrm{O} 1$ and $\mathrm{O} 3$ atoms by $0.062(1) \AA . \operatorname{Pd}(\mathrm{II})$ atom forms a five-membered chelate ring with phen, and a seven-membered chelate ring with PHT. The seven-membered chelate ring is largely deformed to construct a ship-shaped conformation for the two carboxylate groups, which are both shifted from the benzene plane in a nearly same degree with the torsion angles: C2-C1-C7-O1: $-60.0(3)^{\circ}, \quad \mathrm{C} 2-\mathrm{C} 1-\mathrm{C} 7-\mathrm{O} 2: \quad 122.7(2)^{\circ}, \quad \mathrm{C} 1-\mathrm{C} 2-\mathrm{C} 8-\mathrm{O} 3$ : $62.3(3)^{\circ}$ and $\mathrm{C} 1-\mathrm{C} 2-\mathrm{C} 8-\mathrm{O} 4:-118.5(2)^{\circ}$. The whole structure is completely distinct from complexes $\mathbf{1}$ and $\mathbf{2}$, with the dihedral angle of the phen plane and the benzene plane being $89.27(9)^{\circ}$. This means that the benzene ring of PHT places nearly perpendicular to the phen plane. Furthermore, as

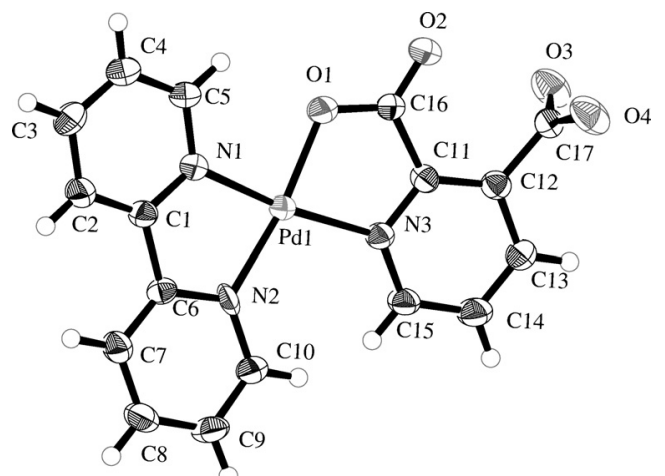

Fig. 4. ORTEPII Drawing of Complex 2, Showing 50\% Probability Displacement Ellipsoids

The water molecules involved in the unit are omitted for the clarification of the basic Pd(II) coordination geometry.

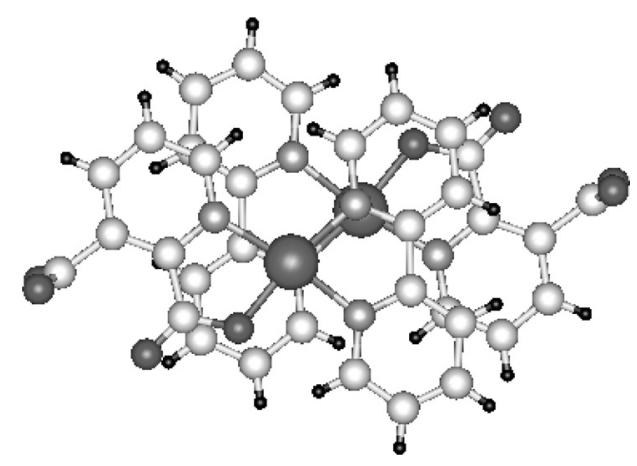

Fig. 5a. A View of $\pi-\pi$ Interaction between the Adjacent Pd(II) Moiety in Complex 2 shown in Fig. 7a, this steric arrangement results in the neighboring molecules intersecting with each other, with paralleling phen planes being perpendicular to benzene plane in the packing. The outer planes of the adjacent phen planes stack layer by layer forming $\pi$ stacking interaction along (100) axis with the interplanar distances of $3.493(3) \AA$ and 3.500(1) A alternately (shown in Fig. 7b).

The structure of complex 4 is shown in Fig. 8. It has a very similar structure with complex 3. The Pd(II) atom lies at the center of the cis-square-planar geometry, in which the $\mathrm{Pd}(\mathrm{II})$ atom is bonded to two $\mathrm{N}$ atoms of bpy ligand and two $\mathrm{O}$ atoms of PTH. It deviated from the mean plane constructed from the N1, N2, O1 and $\mathrm{O} 2$ atoms by $0.072(1) \AA$. The two pyridine rings of bpy are about coplanar, twisted only $2.74(13)^{\circ}$. PHT molecule is perpendicular to bpy molecule with the dihedral angles of benzene plane to N1 pyridine plane and N2 pyridine plane being $89.4(1)^{\circ}$ and $87.9(1)^{\circ}$, respectively. In this case, PHT molecule shows the complete same steric geometry (shown in Fig. 9a) as that in complex 3 . The crystal structure is stabilized by the strong $\pi$ stacking interaction between bpy molecules along (100) axis with the inter planar distances between the parallel bpy plane layers of 3.500(6) $\AA$ and 3.426(6) $\AA$ alternately (shown in Fig. 9b).

The hydrogen-bond networks are indicated by dashed lines in the packing figures involving the disordered water molecules, and the data are shown in Table 6. In 1, shown in Fig. $3 \mathrm{~b}$, four hydrated water molecules $\mathrm{O} 5, \mathrm{O} 6, \mathrm{O} 7$ and $\mathrm{O} 8$ atoms

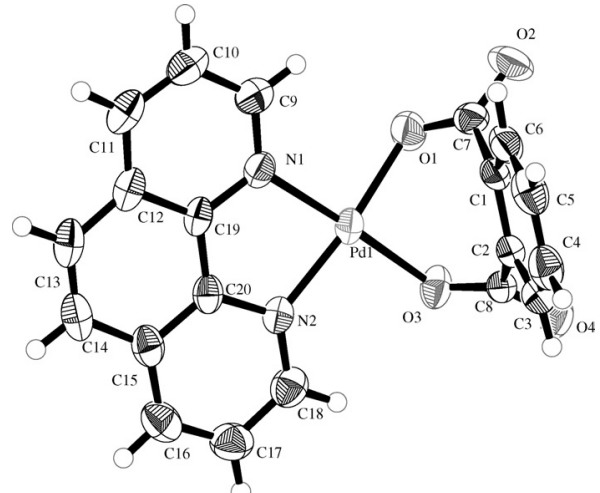

Fig. 6. ORTEPII Drawing of Complex 3, Showing 50\% Probability Displacement Ellipsoids

The water molecules involved in the unit are omitted for the clarification of the basic Pd(II) coordination geometry.

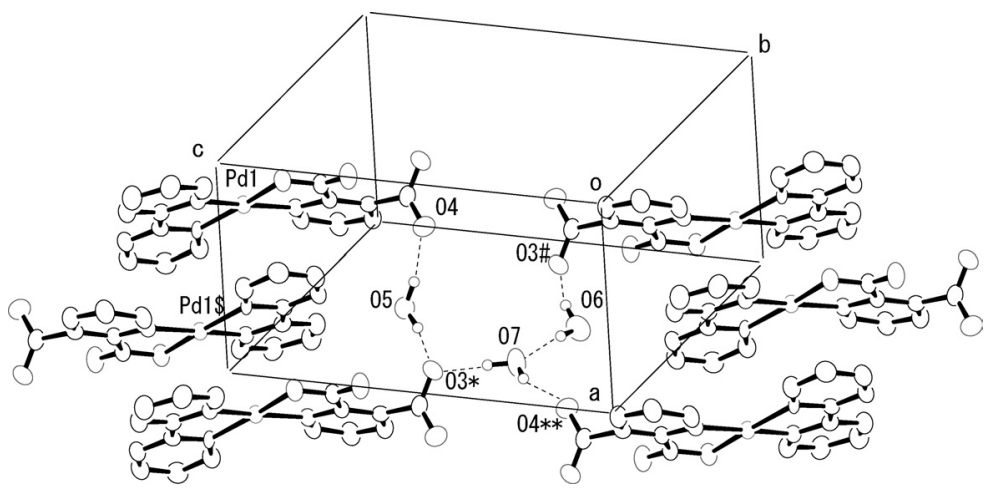

Fig. 5b. A View of Packing Pattern in Complex 2 Including H-Bonds Indicated with Dashed Lines $*: 1+X,+Y,+Z, * *: 2-X, 1-Y, 1-Z, \#: 1-X, 1-Y, 1-Z, s: 1-X,-Y, 2-Z$. 
are linked to each other by intermolecular hydrogen bonds. Moreover, $\mathrm{O} 5$ atom acts as a donor to $\mathrm{O} 4$ and $\mathrm{O} 4(-1 / 2+X$, $1 / 2-Y,+Z$ ) atoms, as well as $\mathrm{O} 8$ atom providing $\mathrm{H}$ atoms to $\mathrm{O} 2(3 / 2-X, 1 / 2+Y, 1-Z)$ and $\mathrm{O} 3(-1 / 2+X, 1 / 2-Y,-1+Z)$ atoms, which resulting in the complex molecules connected along $\mathrm{a}$ and $\mathrm{b}$ axis. In $\mathbf{2}$, shown in Fig. 5b, the overall complex molecules are stabilized by the $\mathrm{O} 5-\mathrm{H} 12 \cdots \mathrm{O} 4$ and O5-H13 $\cdots \mathrm{O} 4(1+X,+Y,+Z)$ along a axis together with the $\pi-\pi$ interaction running in the same direction, and by the O7-H14 $\cdots \mathrm{O} 3(1+X,+Y,+Z)$ and $\mathrm{O} 7-\mathrm{H} 15 \cdots \mathrm{O} 4(2-X$, $1-Y, 1-Z)$ in $c$ axis. In 3, shown in Fig. $7 \mathrm{~b}, \mathrm{O} 5$ atom and disordered $\mathrm{O} 6, \mathrm{O} 7$ atom each plays an important role in the hydrogen bond network to form chains along $a$ and $c$ axis. Especially $\mathrm{O} 7$ water has only half occupancy in relation to O7 $(1-X,-Y, 2-Z)$ atom locating at its symmetry position. In 4, shown in Fig. 9b, O5 atom is located in a special position in the unit with the coordinate parameter $(0,0,0.5)$ which is the symmetry center of the O6 and O6 $(-X,-Y$, $1-Z$ ). The main hydrogen bonds exist among the hydrated water molecules, while another hydrogen bond O6-H17 $\cdots \mathrm{O} 4(1 / 2-X,-1 / 2+Y, 1 / 2-Z)$ adjoins the related complex molecules. In all compounds, there is more than one water molecule in the crystal unit, and all of the water molecules participate in formation of the hydrogen bond network,

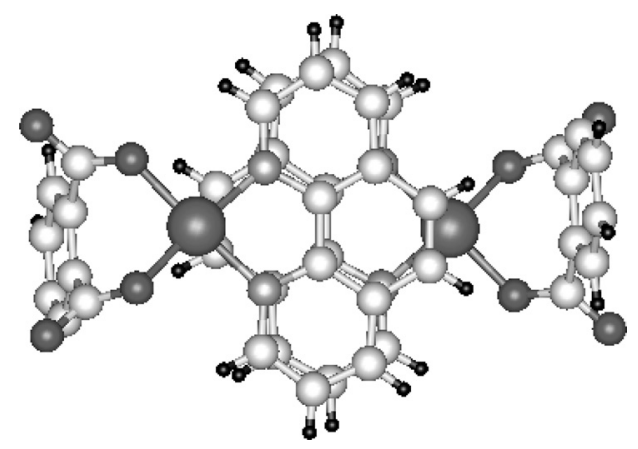

Fig. 7a. A View of $\pi-\pi$ Interaction between the Adjacent Pd(II) Moiety in Complex 3 which can be classified to two types: one is the intermolecular hydrogen bond between the hydrated and disordered water molecules, by which the water cluster around the $\operatorname{Pd}($ II) moiety is stabilized. Another is the intermolecular hydrogen bond between the water $\mathrm{O}$ atoms and the carboxylate $\mathrm{O}$ atoms from the ligands. For this type of interaction, each compound is stabilized along two dimensional directions, together with the significant $\pi-\pi$ interaction between the paralleling layers.

The coordination bond distances indicate that cayboxylate $\mathrm{O}$ atom either in PDCA ligand or in PHT ligand (in this case, one of the $\mathrm{O}$ atom) has the strongest interaction with $\mathrm{Pd}$ (II) atom with the bond $\mathrm{Pd}-\mathrm{O}$ distance value ranging from $1.964(1) \AA$ to $1.984(3) \AA$. The interaction between Pd(II) atom and the other coordinated atoms is weakened according to the following sequence: for $\mathrm{O}$ atoms, $\mathrm{Pd}-\mathrm{O}$ (PDCA and one of carboxylate $\mathrm{O}$ atom in $\mathrm{PHT}$ ) $>\mathrm{Pd}-\mathrm{O}$ (another carboxylate $\mathrm{O}$ atom in $\mathrm{PHT}$ ); for $\mathrm{N}$ atoms, $\mathrm{Pd}-\mathrm{O}$ (phe and bpy) $>$ Pd-O (PDCA).

Comlexes $\mathbf{1}$ and $\mathbf{2}$ have the similar coordination environ-

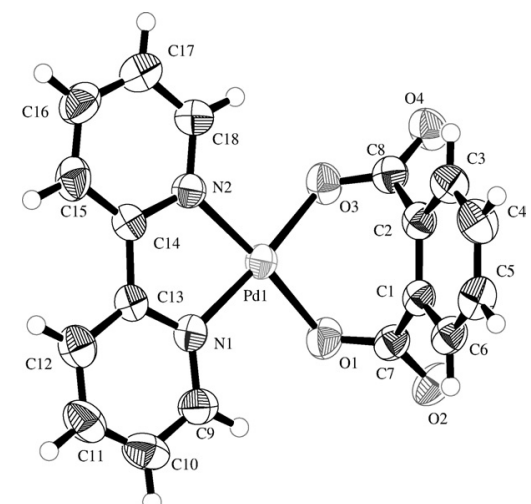

Fig. 8. ORTEPII Drawing of Complex 4, Showing 50\% Probability Displacement Ellipsoids

The water molecules involved in the unit are omitted for the clarification of the basic $\mathrm{Pd}(\mathrm{II})$ coordination geometry.

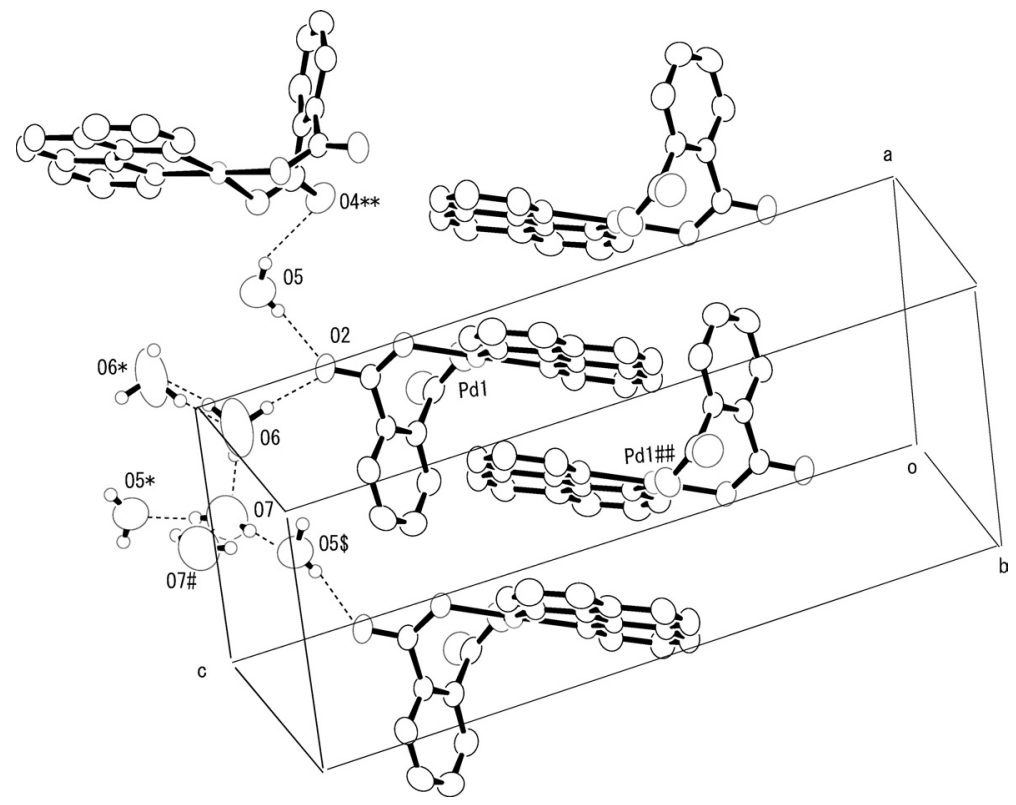

Fig. 7b. A View of Packing Pattern in Complex 3 Including H-Bonds Indicated with Dashed Lines

$*: 2-X,-Y, 2-Z$, \#: $1-X,-Y, 2-Z, * *: 5 / 2-X,-1 / 2+Y, 3 / 2-Z, s:-1+X,+Y,+Z$, \#: $1-X,-Y, 1-Z$. 


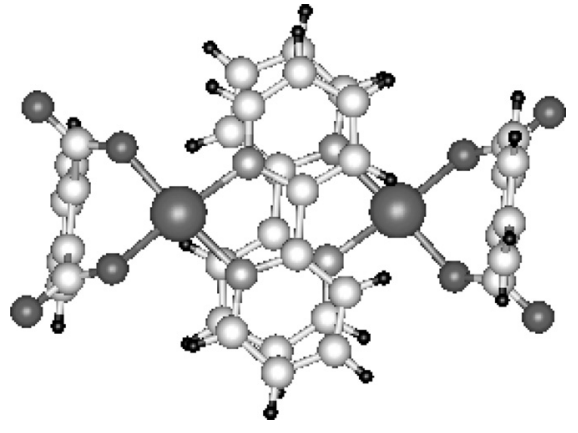

Fig. 9a. A View of $\pi-\pi$ Interaction between the Adjacent Pd(II) Moiety in Complex 4

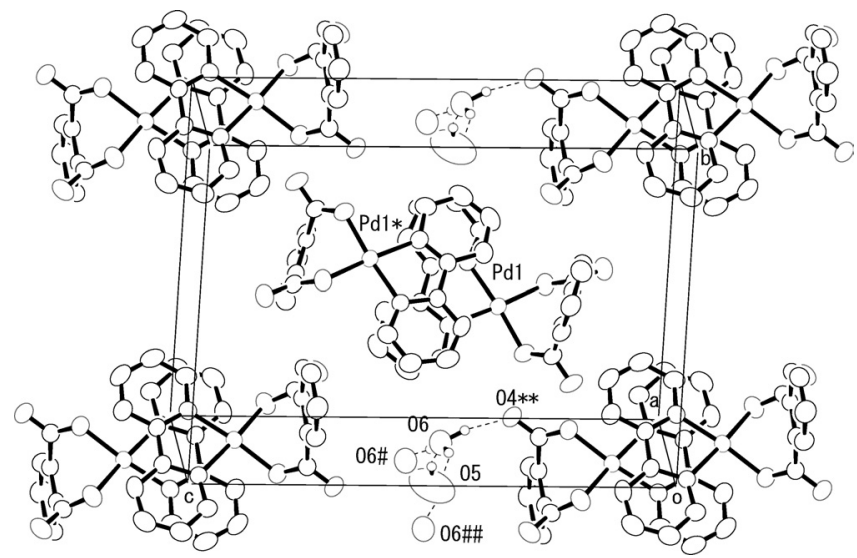

Fig. 9b. A View of Packing Pattern in Complex 4 Including H-Bonds Indicated with Dashed Lines

*: $1-X, 1-Y, 1-Z, * *: 1 / 2-X,-1 / 2+Y, 1 / 2-Z, \#: 1-X,-Y, 1-Z$, \#: $-X,-Y$ $1-Z$.

ment, in both of which PDCA ligands provide $\mathrm{N}$ atom and one of the carboxylate $\mathrm{O}$ atom at ortho position against $\mathrm{N}$ atom. In the $\mathrm{Pd}(\mathrm{II})$ complexes with dianionic 2,6-PDCA, ${ }^{14)}$ the 2,6-PDCA behaves as a tridentate $\mathrm{O}, \mathrm{O}^{\prime}, \mathrm{N}$ ligand as mononuclear complexes except the structure of $\left[\mathrm{Pd}\left(\mathrm{PBu}_{3}\right)\left(2,6\right.\right.$-PDCA)] (where $\mathrm{PBu}_{3}$ is tributylphosphine), in which 2,6-PDCA behaves as an $\mathrm{N}, \mathrm{O}$ bidentate ligand in $\mathrm{N}, \mathrm{O}^{\prime}$-bridging dinuclear complex. In all of the transition metal complexes of 2,6-PDCA such as $\mathrm{Mn},{ }^{15)} \mathrm{Cu}(\mathrm{II})^{16)}$ or $\mathrm{Zn}(\mathrm{II}),{ }^{16)}$ with lanthanoid metals such as $\mathrm{La}(\mathrm{III})^{17)}$ or $\mathrm{Ce}(\mathrm{III})^{18)}$ or with an alkaline metal such as $\mathrm{Li}(\mathrm{I}),{ }^{19)} 2,6-$ PDCA behaves as the dianionic tridentate ligand, in which two $\mathrm{O}$ atoms of the two carboxylate groups in both sides of $\mathrm{N}$ atom and the pyridine $\mathrm{N}$ atom are bonded to the metal ions. Therefore, in the presence of other bidentate N, $\mathrm{N}^{\prime}$ heterocyclic ligands, phen and bpy, the tridentate 2,6-PDCA behaves preferably as a bidentate $\mathrm{N}, \mathrm{O}$ ligand. In complex $\mathbf{2}$, although the two carboxylate groups located in neighboring positions to each other, they do not participate in the coordination at the same time. Similar coordination mode is observed with the case of the metal complexes of 2pyridinecarboxylic acid (2-PCA) or its analogues compounds. $^{20-22)}$ This is also similar with the crystal structures of the transition metal complexes of 2,3-PDCA such as $\mathrm{Ni}(\mathrm{II}), \mathrm{Mn}(\mathrm{II})^{23)}$ or $\mathrm{Co}(\mathrm{II}),{ }^{24)}$ in which 2,3 -PDCA behaves as a bidentate ligand providing $\mathrm{N}$ atom and one of the carboxylate $\mathrm{O}$ atom at ortho position against $\mathrm{N}$ atom. In the common case, $\mathrm{Pd}(\mathrm{II})$ atom needs the two coordinate atoms in ortho positions to each other to form four coordination geometry and a five-membered chelate ring. This is remarkably distinct from complexes 3 and $\mathbf{4}$, in which PHT includes two ortho carboxylate groups.

The chelate angles $\mathrm{N}-\mathrm{Pd}-\mathrm{O}$ for 2,6-PDCA (complex 1) and 2,3-PDCA (complex 2) are very resemble to each other, but larger than those N-Metal-O angles appeared in the square planar coordination geometry of the usual transition metal complexes: 2,6-PDCA with $\mathrm{Cu}(\mathrm{II})$ (18), 74.50(7)-80.10(8) ${ }^{\circ} ; \mathrm{Zn}(\mathrm{II})(18), 73.21(8)-79.22(8)^{\circ}$, 2,3PDCA, with $\mathrm{Co}(\mathrm{II})(25), 77.44(7)^{\circ}$ or 2 -PCA with $\mathrm{Cd}(\mathrm{II})$, $72.0(1)^{\circ}, \mathrm{Mn}(\mathrm{II}), 74.61(7)^{\circ} .^{25)}$

The coordination geometry around $\mathrm{Pd}(\mathrm{II})$ atom of complex 3 and $\mathbf{4}$ is very resemble to that of [Pd(phen)(CBDCA)] and $[\mathrm{Pd}($ bpy $)(\mathrm{CBDCA})] .{ }^{7)}$ The two carboxylate $\mathrm{O}$ atoms substituted at the same position on CBDCA coordinated to $\mathrm{Pd}(\mathrm{II})$ atom with the bond distances, 2.003(2) $\AA$ and 2.005(2) $\AA$ for $[\mathrm{Pd}(\mathrm{phen})(\mathrm{CBDCA})]$, and 2.002(2) $\AA$ and $2.004(2) \AA$ for $[\mathrm{Pd}(\mathrm{bpy})(\mathrm{CBDCA})]$. The chelate angle of $\mathrm{O}-\mathrm{Pd}-\mathrm{O}$, 91.3(2) for $[\operatorname{Pd}($ phen $)(C B D C A)]$ and $91.68(7)^{\circ}$ for [Pd(bpy)(CBDCA)] are a little larger than those of complexes 3 and 4 . The phen $\mathrm{N}-\mathrm{Pd}-\mathrm{N}$ chelate angle in complex $\mathbf{3}$ and the bpy Nd chelate angle in complex $\mathbf{4}$ are resemble to $[\mathrm{Pd}($ phen $)(\mathrm{CBDCA})], \quad 80.80(8)^{\circ}$ and $[\mathrm{Pd}(\mathrm{bpy})(\mathrm{CBDCA})]$, $82.2(2)^{\circ}$.

Although two carboxylate groups have the same geometry environment in PHT, their coordination force is slightly different. They respectively act as a strong donor and a weak donor in both complexes 3 and 4. Although as reported in almost all cases, the phthalate dianion acts as a bridging ligand using $\mathrm{O}$ atoms from both carboxylate groups, in complexes 3 and 4 it contributes to the coordination as a bidentate $\mathrm{O}, \mathrm{O}^{\prime}$ ligand, distinct from its $\mathrm{Cu}(\mathrm{II}), \mathrm{Zn}$ (II) and $\mathrm{Co}(\mathrm{II})$ complexes. $^{26-28)}$ These results suggest that the $\mathrm{Pd}(\mathrm{II})$ atom coordinate easily to the pyridine $\mathrm{N}$ atom than the carboxylate $\mathrm{O}$ atom, and also to $\mathrm{O}$ atoms of two carboxylate groups in ortho positions to each other.

Characteristically, the molecular packing patterns in complexes $\mathbf{3}$ and $\mathbf{4}$ are very similar in such a way that the heterocyclic ligand layers are alternately arranged parallel to each other along a axis and these layers themselves are stabilized by strong $\pi$ stacking interaction. In these complexes, due to the peculiar structure of the PHT dianion, the two carboxylate groups are nonplanar with themselves and with the benzene ring. When two $\mathrm{O}$ atoms from two carboxylate groups in ortho-position participates the coordination, the basic coordination is that two moiety intersect with each other at near $90^{\circ}$ This coordination mode is easy to form parallel layer with the adjacent molecules intervening with each other and thus avoid the steric hindrance. This mode is different from the complexes $\mathbf{1}$ and $\mathbf{2}$, in which the five-membered chelate ring formed by $\mathrm{Pd}(\mathrm{II})$ atom and the heterocyclic atoms mainly conform the packing effect.

\section{Conclusion}

The coordination modes of $\mathrm{Pd}(\mathrm{II})$ with the different ligand atoms, $\mathrm{N}$ atoms of the aromatic heterocyclic ligands, and $\mathrm{N}$ and $\mathrm{O}$ atoms of the dianionic pyridine dicarboxylate ligands and benzenedicarboxylate ligand have been structurally clarified. The interaction between $\mathrm{Pd}(\mathrm{II})$ atom and ligand atoms 
are discussed including the packing effects. The structural features characterized in this study are useful for further investigation of the biochemical behavior of the Pd(II) complexes.

\section{References and Notes}

1) Lee K. I., Tashiro T., Noji M., Chem. Pharm. Bull., 42, 702-703 (1994).

2) Ali M. A., Mirza A. H., Butcher R. J., Tarafder M. T. H., Keat T. B., J. Inorg. Biochem., 92, 141-148 (2002).

3) Rau T., van Eldik R., Metal Ions in Biological Systems, 32, 339-378 (1996).

4) Mansuri-Torshizi H., Ghadimy S., Akbarzadeh N., Chem. Pharm. Bull., 49, 1517-1520 (2001).

5) Shehata M., Transition Met. Chem., 26, 198-204 (2001).

6) Okabe N., Hagihara K., Odoko M., Muranishi Y., Acta Crystal., C60, $150-152$ (2004).

7) Muranishi Y., Okabe N., Acta Cryst., C60, 47-50 (2004).

8) Okabe N., Muranishi Y., Aziyama T., Acta Cryst., E59, 936-938 (2003).

9) Taylor B. F., King C. A., FEMS Microbiology Lett., 44, 401-405 (1987).

10) Altomare A., Burla M., Camalli M., Cascarano G., Giacovazzo C., Guagliardi A., Moliterni A., Polidori G., Spagna P., J. Appl. Cryst., 32, 115-119 (1999).

11) Crystal Structure Analysis Package, Rigaku and Rigaku/MSC. 9009 New Trails Dr. The Woodlands TX 77381 USA (2000-2004).

12) Sheldrick G. M., "SHELXL97," University of Götingen, Germany,
1997.

13) Bardwell D. A., Crossley J. G., Jeffery J. C., Orpen A. G., Psillakis E., Tilley E. E. M., Ward M. D., Polyhedron, 13, 2291-2300 (1994).

14) Espinet P., Miguel J. A., Inorg. Chem., 35, 2287-2291 (1996).

15) Okabe N., Oya N., Acta Cryst., C56, 1416-1417 (2000).

16) Okabe N., Oya N., Acta Cryst., C56, 305-307 (2000).

17) Okabe N., Kyoyama H., Acta Cryst., E58, m226-m227 (2002).

18) Okabe N., Kyoyama H., Fujimoto A., Acta Cryst., E58, m354 - m356 (2002).

19) Odoko M., Kusano A., Oya N., Okabe N., Acta Cryst., C58, m215$\mathrm{m} 216$ (2002).

20) Odoko M., Isomoto N., Okabe N., Acta Cryst., E57, m371-m372 (2001).

21) Okabe N., Muranishi Y., Wada Y., Acta Cryst., C58, m511-m513 (2002).

22) Okabe N., Muranishi Y., Odoko M., Acta Cryst., C60, m345-m347 (2004).

23) Goher M. A. S., Youssef A. A., Zhou Z. Y., Mak T. C. W., Polyhedron, 12, 1871-1878 (1993)

24) Okabe N., Miura J., Shimosaki A., Acta Cryst., C52, 1610-1612 (1996).

25) Okabe N., Koizumi M., Acta Cryst., C54, 288-290 (1998).

26) Bakalbassis E. G., Paschalidis D. G., Inorg. Chem., 37, 4735-4737 (1998).

27) Baca S. G., Simonov Y. A., Gerbeleu N. V., Gdaniec M., Bourosh P. N., Timco G. A., Polyhedron, 20, 831-837 (2001).

28) Simonov Y. A., Gdaniee M., Filippova I. G., Baca S. G., Timco G. A., Gerbeleu N. V., Russ. J. Coord. Chem., 27, 353-359 (2001). 